\title{
Pollen preferences among the bee species visiting apple (Malus pumila) in New York
}

\author{
Laura RuSSO $^{1}$, Bryan DANFORTH ${ }^{2}$ \\ ${ }^{1}$ Trinity College Dublin, Botany Department, Dublin, Dublin Co. WD 91 D 12, Ireland \\ ${ }^{2}$ Cornell University, Comstock Hall, Ithaca, NY 148050, USA
}

Received 23 April 2017 - Revised 18 May 2017 - Accepted 2 June 2017

\begin{abstract}
Maintaining a diverse and abundant wild bee community is essential for sustainable agricultural pollination, especially in crops in which wild bees are effective pollinators. Many land managers have an economic interest in encouraging healthy wild bee populations, but it is not always clear how to accomplish this. In apple orchards, wild bees play a critical role as pollinators, but are active before most forbs begin to flower. To investigate which flowering plant species might serve as alternative pollen hosts for the most abundant wild bee species collected in eastern apple orchards, we analyzed the pollen carried by 15 wild bee species and 1 managed bee species (Apis mellifera) collected during apple bloom. We identified the pollen grains carried by these bees and found that the majority of alternative pollen hosts for apple visitors are early blooming tree species, including six other tree genera. This may partly explain why the presence of forest fragments is an important predictor of bee abundance and species richness in New York apple orchards.
\end{abstract}

agricultural pollination / alternative pollen hosts / floral provisioning / pollen analysis / pollination services / wild bee communities

\section{INTRODUCTION}

Bees are important pollinators for many agricultural crops (Klein et al. 2007), and wild bees have been shown to contribute demonstrably to yield in diverse crops grown around the world (Garibaldi et al. 2013). The cultivation of pollinator-dependent crops is also increasing faster than the rate of honeybee production, which suggests that wild, unmanaged bees are an increasingly important, but sometimes underappreciated, component of agricultural pollination (Aizen et al. 2008). Economically important mass flowering crops that host a diverse wild bee fauna include apples (Russo et al.

Electronic supplementary material The online version of this article (doi:10.1007/s13592-017-0525-3) contains supplementary material, which is available to authorized users.

Corresponding author: L. Russo, russola@tcd.ie Manuscript editor: Alexandra Klein
2015), blueberries (Tuell et al. 2009), strawberries (Connelly et al. 2015), cranberries (Mackenzie and Averill 1995), canola (Morandin and Winston 2005), and watermelon (Kremen et al. 2002). A number of studies have demonstrated an important role of wild bees in apple pollination, especially in eastern North America where orchards are typically small and embedded in a matrix of natural habitat (Mallinger and Gratton 2015; Martins et al. 2015; Blitzer et al. 2016; Russo et al. 2015).

Given the important role that wild bees play in crop pollination, there are clear economic incentives for developing effective strategies for maintaining and conserving wild bee diversity in agroecosystems. However, the composition of the wild bee fauna varies widely among crops, and the strategies for conserving wild bees in one crop system may not be appropriate for another, different crop system. Floral resources, including pollen and nectar, are essential for bee survival and reproduction, but host plant preferences are 
unknown for many wild bee species (Tuell et al. 2008; Russo et al. 2013). Before one can develop an effective management plan for maintaining wild pollinator diversity and abundance, one needs to know the host plant preferences of individual wild bee species in order to generalize across the entire community of wild pollinators in a particular agroecosystem.

In this study, we investigated the pollen host plant preferences of wild and managed bees that are important and abundant pollinators of apple (Malus pumila) in eastern North America. Pollen is a critical component of the bee diet, representing the sole protein source for most bee species. Variation in pollen quality can have significant impacts on bee health and fitness (Genissel et al. 2002; Roulston and Cane 2002; Schmidt et al. 1987). Pollens vary widely in protein and lipid content, which are both thought to be essential determinants of pollen nutritional quality for solitary and social bees (Roulston and Cane 2002; Vaudo et al. 2016). Generalist bees have been shown to develop better on a mixed pollen diet (Eckhardt et al. 2014), suggesting that pollen diversity per se may be important for larval growth and development. The majority of bees tend to collect pollen from several species of plants over the course of their lives to provision their offspring (Waser et al. 1996), and there is evidence that bees can be selective about which pollen types they collect to optimize their nutrition (Roulston and Cane 2002; Vaudo et al. 2015; but see Pernal and Currie 2001).

We show that early flowering tree species and weedy forbs constitute an important source of pollen for 16 species of early spring apple visitors. Our results are consistent with previous studies that have documented an important role for natural habitat (mostly forest) in sustaining diverse and abundant wild bee communities in and around eastern apple orchards (Park et al. 2015). This study shows that maintaining a diversity of pollen hosts is important for eastern apple growers who wish to maintain a diverse and abundant wild bee fauna in and around their orchards.

\section{MATERIAL AND METHODS}

We net-collected wild bees and managed honeybees in 28 apple orchards of the Finger Lakes region of western New York from 2008 to 2013 and 21 in the Hudson Valley of eastern New York in 2015 (Russo et al. 2015). These orchards varied on gradients of pesticide usage (from organic to conventional) and percent natural area in the surrounding habitat (20-65\%, Park et al. 2015). The natural area surrounding the orchards tended to be forest fragments and correlated positively, while pesticide usage correlated negatively with bee species richness and abundance (Park et al. 2015). Bees visiting apple blossoms were net collected in standardized $15 \mathrm{~min}, 50-\mathrm{m}$ transects and in general collections that lasted at least 15 min (Russo et al. 2015). All bee collections took place during apple bloom, which generally occurs toward the end of April or beginning of May and lasts for approximately 2 weeks. Thus, pollen carried by the bees was from species that were co-flowering with the apple trees. Orchards were sampled a minimum of three times in the morning and three times in the afternoon during each flowering season. All bees collected during these samples were pinned, labeled, and identified to species. The specimens are housed in the Cornell University Insect Collection (http://cuic.entomology.cornell.edu/).

\subsection{Pollen reference library}

We surveyed 15 of the 28 apple orchards in the Finger Lakes region and identified and collected pollen samples from all flowering plant species from April 1 to October 29, 2014. We stained the pollen grains with basic fuchsin and prepared slides for each pollen type, taking multiple measurements to estimate the dimensions of each pollen reference species. Photographs of pollen grains and the associated plant species were stored together online at a publicly available pollen library (http://blogs.cornell.edu/pollengrains/). To see examples of reference pollen compared to pollen identified in the counts for the primary pollen types we found, see supplementary Fig. S1.

\subsection{Species selection}

In order to identify the most important alternative pollen sources for wild and managed bees in eastern apple orchards, we analyzed 
the pollen carried by 16 species of bees collected in apple orchards during peak bloom in central New York (see Russo et al. 2015 for collection details). The majority of our counts focused on the pollen carried externally by female pollen-collecting bees. We randomly selected 10 individuals from species represented by more than 30 specimens in six of the most abundant Andrena species representing five different subgenera (An. crataegi, $A n$. hippotes, An. regularis, An. miserabilis, An. nasonii, and An. vicina). To provide a broad taxonomic representation, we sampled 10 specimens from representative species of each of the most common apid genera (Bombus impatiens, Apis mellifera, Ceratina calcarata, Xylocopa virginica), the three most common halictid genera (Lasioglossum hitchensis, Augochlora pura, and Halictus rubicundus), and the only common megachilid and colletid genera (Osmia cornifrons and Colletes inaequalis). Female pollen-collecting bees are typically considered to be the primary pollinators of flowers, but little is known about the pollen carried by male and/or cleptoparasitic bees, which do not actively collect pollen for offspring and lack pollen collection structures. Because the foraging behavior of these bees is not relevant to the specialization of the bee species (Wray and Elle 2016), they are often ignored in studies of pollen host composition. Cleptoparasitic bees are known to collect nectar (Bogusch 2003), but less is known about their efficacy as pollinators or their own pollen consumption. In certain systems, male bees have been shown to potentially carry pollen in long distances (Ne'eman et al. 2006) and carry sufficient pollen to effect pollination (Pascarella 2010; Fliszkiewicz et al. 2011). Because males and cleptoparasites were a small, but non-trivial component of our collections, we also chose to analyze the pollen carried by males in two pollen-collecting species in which males were more abundant than females (An. crataegi and $X$. virginica), as well as both the males and females of a genus of cleptoparastic bees (Nomada spp.). Finally, we examined both the internal and external pollen of a bee species known to carry pollen both in the scopa and inside the crop (Ce. calcarata).

\subsection{Pollen counting}

Our pollen counting methodology follows the methods developed by Edens-Meier et al. (2011) (see also Bernhardt 1987). Pollen was washed from the bees onto a slide using ethyl acetate. The bees were washed twice per sample (the two washes were separated by the left and right coverslips) in order to maximize removal of grains (Fig. S2). The ethyl acetate and pollen grains were allowed to dry for approximately $5 \mathrm{~min}$ and then stained with basic fuchsin (Carlberla's solution, Edens-Meier et al. 2011). After 2 to $3 \mathrm{~min}$, the mixture was covered with a coverslip and allowed to set overnight before pollen grains were counted.

We washed pollen from the bodies of 10 female individuals randomly selected from the bee specimens collected in the apple orchards (stored in the Cornell University Insect Collection) of each of 15 different bee species and 5 undetermined individuals of the genus Nomada from the apple orchard surveys (Table I). In species where males outnumbered females (X. virginica, An. crataegi, and male Nomada spp.), we also did pollen washes on 10 male specimens. We found that the mix of nectar and pollen stored in the corbicula of A. mellifera had to be dissolved in distilled water before being stained and set on the slide. For this reason, we conducted two separate washes (on two different sets of 10 individuals) for A. mellifera. One wash consisted exclusively of corbicular pollen, and the other wash consisted of a whole body wash, as described above for the wild bees included in the study). In all species with a sample size of 10 specimens (i.e., all except female Nomada spp.), bees were randomly selected from the collection for pollen analysis. For female Nomada, we sampled all available individuals.

We also counted the pollen carried internally in the crop of Ce. calcarata, as Ce. calcarata is likely to store pollen both internally and externally (Jander 1976). The external pollen of the bees was first washed and counted; subsequently, the abdomens of the same individuals were removed and 
Table I. Details on specimens sampled, number of grains counted, and number of pollen types

\begin{tabular}{|c|c|c|c|c|c|c|}
\hline Sex/wash & Species & $\begin{array}{l}\text { Mean pollen } \\
\text { grains } \\
\text { counted }\end{array}$ & $\begin{array}{l}\text { No. of } \\
\text { individuals }\end{array}$ & $\begin{array}{l}\text { No. of pollen } \\
\text { types }>3 \% \\
\text { (species wide) }\end{array}$ & $\begin{array}{l}\text { Mean no. of } \\
\text { pollen types per } \\
\text { individual }\end{array}$ & Nesting habit \\
\hline \multicolumn{7}{|l|}{ Female } \\
\hline \multirow[t]{16}{*}{ External } & Andrena crataegi & $400 \pm 34$ & 10 & 5 & $2.3 \pm 0.67$ & Ground \\
\hline & An. hippotes & $530 \pm 25.1$ & 10 & 6 & $2.5 \pm 1.18$ & Ground \\
\hline & An. miserabilis & $463 \pm 22.9$ & 10 & 3 & $2 \pm 1.25$ & Ground \\
\hline & An. nasonii & $607 \pm 146$ & 10 & 4 & $2.6 \pm 0.16$ & Ground \\
\hline & An. regularis & $1199 \pm 341.9$ & 10 & 4 & $2.1 \pm 0.28$ & Ground \\
\hline & An. vicina & $544 \pm 33.2$ & 10 & 3 & $2.3 \pm 1.34$ & Ground \\
\hline & Apis mellifera & $356 \pm 7.6$ & 10 & 3 & $2.4 \pm 1.26$ & Cavity \\
\hline & Augochlora pura & $330 \pm 18.8$ & 10 & 6 & $2.7 \pm 1.01$ & Ground \\
\hline & Bombus impatiens & $302 \pm 24.3$ & 10 & 7 & $2.6 \pm 0.97$ & Cavity \\
\hline & Ceratina calcarata & $181 \pm 60.4$ & 10 & 4 & $3.6 \pm 1.84$ & Stem \\
\hline & Colletes inaequalis & $508 \pm 21.3$ & 10 & 6 & $3.2 \pm 1.03$ & Ground \\
\hline & $\begin{array}{l}\text { Halictus } \\
\text { rubicundus }\end{array}$ & $382 \pm 14.3$ & 10 & 3 & $2.3 \pm 0.67$ & Ground \\
\hline & $\begin{array}{l}\text { Lasioglossum } \\
\text { hitchensi }\end{array}$ & $290 \pm 40.5$ & 10 & 3 & $2 \pm 0.82$ & Ground \\
\hline & Nomada spp. & $381 \pm 43.8$ & 5 & 5 & $4 \pm 0.82$ & Cleptoparasite \\
\hline & Osmia cornifrons & $394 \pm 35$ & 10 & 3 & $2 \pm 0.82$ & Stem \\
\hline & Xylocopa virginica & $386 \pm 18.9$ & 10 & 4 & $2.6 \pm 0.97$ & Cavity \\
\hline Internal & Ce. calcarata & $382 \pm 33.6$ & 10 & 5 & $2.9 \pm 0.99$ & Stem \\
\hline Scopal & Ap. mellifera & $422 \pm 15.9$ & 10 & 2 & $1.4 \pm 0.7$ & Cavity \\
\hline \multicolumn{7}{|l|}{ Male } \\
\hline \multirow[t]{3}{*}{ External } & An. crataegi & $280 \pm 32.6$ & 10 & 4 & $2.9 \pm 0.99$ & Ground \\
\hline & Nomada spp. & $181 \pm 60.8$ & 10 & 7 & $5.5 \pm 1.18$ & Cleptoparasite \\
\hline & $X$. virginica & $362 \pm 10.2$ & 10 & 6 & $3.9 \pm 1.54$ & Cavity \\
\hline
\end{tabular}

dissected in $80 \%$ ethanol. The crop and other parts of the digestive system containing pollen were removed and placed on a slide. Pollen was further separated from body tissues, and excess body tissues were disposed. The pollen was diluted with ethyl acetate before being stained, as in external pollen slide preparation.

Overall, this resulted in 21 different specieswash-sex combinations, with 16 species of external female washes, 3 species of external male washes, 1 female scopal wash, and 1 female internal wash. Each of these species-wash-sex combinations was represented by 10 individuals randomly selected from the specimens collected in apple orchards while visiting apple blossoms, during apple bloom, with the exception of the female
Nomada, for which we washed all available specimens (5) (Russo et al. 2015).

Slides were examined under an Olympus BX41 light microscope. We counted and classified a minimum of 300 grains of pollen per slide, using at least three random transects across the coverslips, in case of non-random clumping (Online Resource Fig. S2). When there were fewer than 300 pollen grains on the slide, we counted every grain. Pollen morphotypes were assigned for each different type of grain based on size, surface sculpturing, number of pores and furrows, and shape. Reference photos were taken of each pollen type per slide, and sizes were recorded (Fig. S1). A genus or tribe hypothesis was formed for each pollen type based on available 
dichotomous keys (Crompton and Wojtas 1993; Kapp et al. 2000; Lewis et al. 1983), comparison with the pollen reference library (http://blogs.cornell.edu/pollengrains/), and floral phenology surveys in the region and time of year (Russo, unpubl. data). Pollen types representing $<3 \%$ of the total amount of grains per bee species were considered to be contaminants (Table II).

Pollen densities were approximated according to the following index: a value of 1 was assigned if every pollen grain in both coverslips was counted and yet the total count was still less than 300 grains, a 2 was assigned if a full scan of both coverslips was required to reach 300 , a 3 was assigned if a full scan of one coverslip and most of a full scan of the other were required to reach 300 , a 4 was assigned if a full scan of one coverslip was required to reach 300 , a 5 was assigned if more than 20 transects were conducted, a 6 was assigned if 15-20 transects were conducted, a 7 was assigned if 10-14 transects were conducted, an 8 was assigned if 5-9 transects were conducted, a 9 was assigned if $<5$ transects were conducted, and a 10 was assigned if more than 300 grains were counted in the minimum 3 transects required. This index does not represent an absolute number of grains that each individual carried, but is instead a comparative measure of relative pollen density in the washes.

\subsection{Data analysis}

To determine whether our sampling effort was sufficient, we conducted a test for the correlation between the number of pollen types detected and the total pollen count, using a Pearson correlation coefficient (stats base package, R Core Team 2013). We compared male vs female, scopal vs. external, and internal vs external pollen density and number of pollen types with a two-tailed $t$ test (stats base package, R Core Team 2013). We tested whether wash type had a significant effect in the relative proportion of important pollen types (i.e., pollen comprising more than $3 \%$ of the sample) in Ce. calcarata with a linear model (stats base package, R Core Team 2013). To determine whether bee attributes led to clustering in the composition of the pollen gathered, we generated ordination plots of the different sexes and nesting habits with non-metric multidimensional scaling (NMDS) in the package "vegan" (Oksanen et al. 2007).

We used generalized linear mixed effect models using the R package "lme4" (R Core Team 2013; Bates et al. 2015) to determine whether the fixed effects of sex and wash type had a significant effect on the number of pollen types or the proportion of apple carried with the random effects of individual specimen identification number nested within species. We also used generalized linear mixed effect models to determine whether the percent Malus carried differed between the different species-sex-wash combinations. In this model, the fixed effect was the species-sex-wash combination and the random effect was the specimen identification number (Online Resource Table S1).

\section{RESULTS}

We detected a significant negative correlation $\left(P<0.01, R^{2}=-0.31\right)$ between the number of grains counted and the number of pollen types comprising more than $3 \%$ of the total sample (Fig. S3). Pollen densities were lower for males than for females for $X$. virginica $(P<0.01, t$ stat $22.05)$ and An. crataegi $(P<0.01, t$ stat 10.26$)$, but not for the cleptoparasitic genus Nomada $(P=0.21, t$ stat 1.33$)$. The males of An. crataegi and $X$. virginica, which alone comprised $62 \%$ of the male bee abundance in the orchards, carried an equal (An. crataegi, $P=0.05, t$ stat -2.05 ; $X$. virginica, $P=0.93, t$ stat 0.09 ) proportion of Malus pollen, despite having a lower pollen density than their female counterparts (Table II, Figure 1).

Using a mixed effect model, with random effects of specimen ID nested within species, we determined that males in general carried a larger number of different pollen types than females $(P<0.01$, estimate 1.57). This also showed that the scopal load of the honeybee tends to have fewer pollen types than external washes in general $(P<0.01$, estimate -1.13$)$. On the other hand, internal pollen washes did not differ significantly from external washes in general $(P=0.6$, estimate $0.17)$. When we look across all species, the males did not carry a significantly different proportion of 


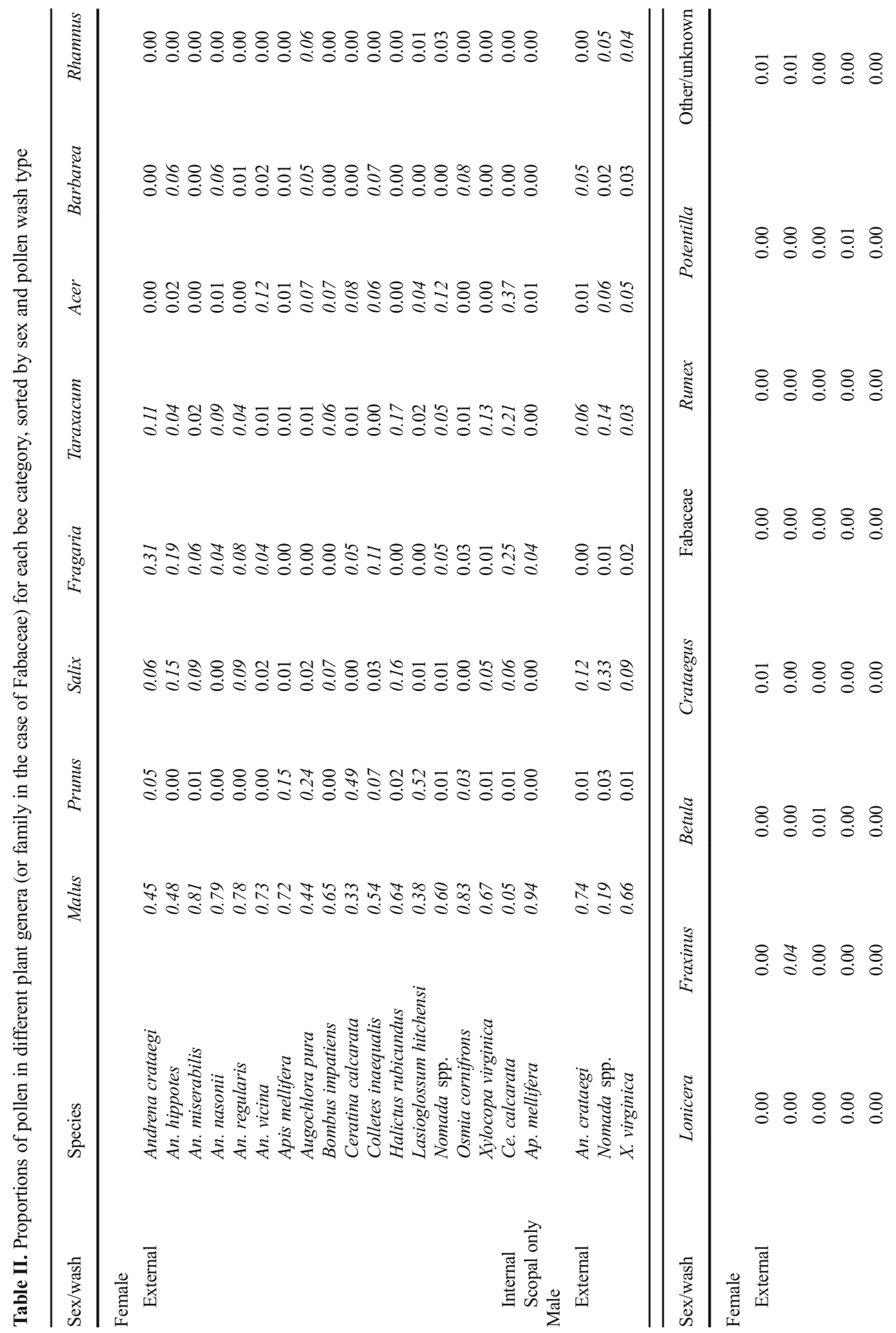




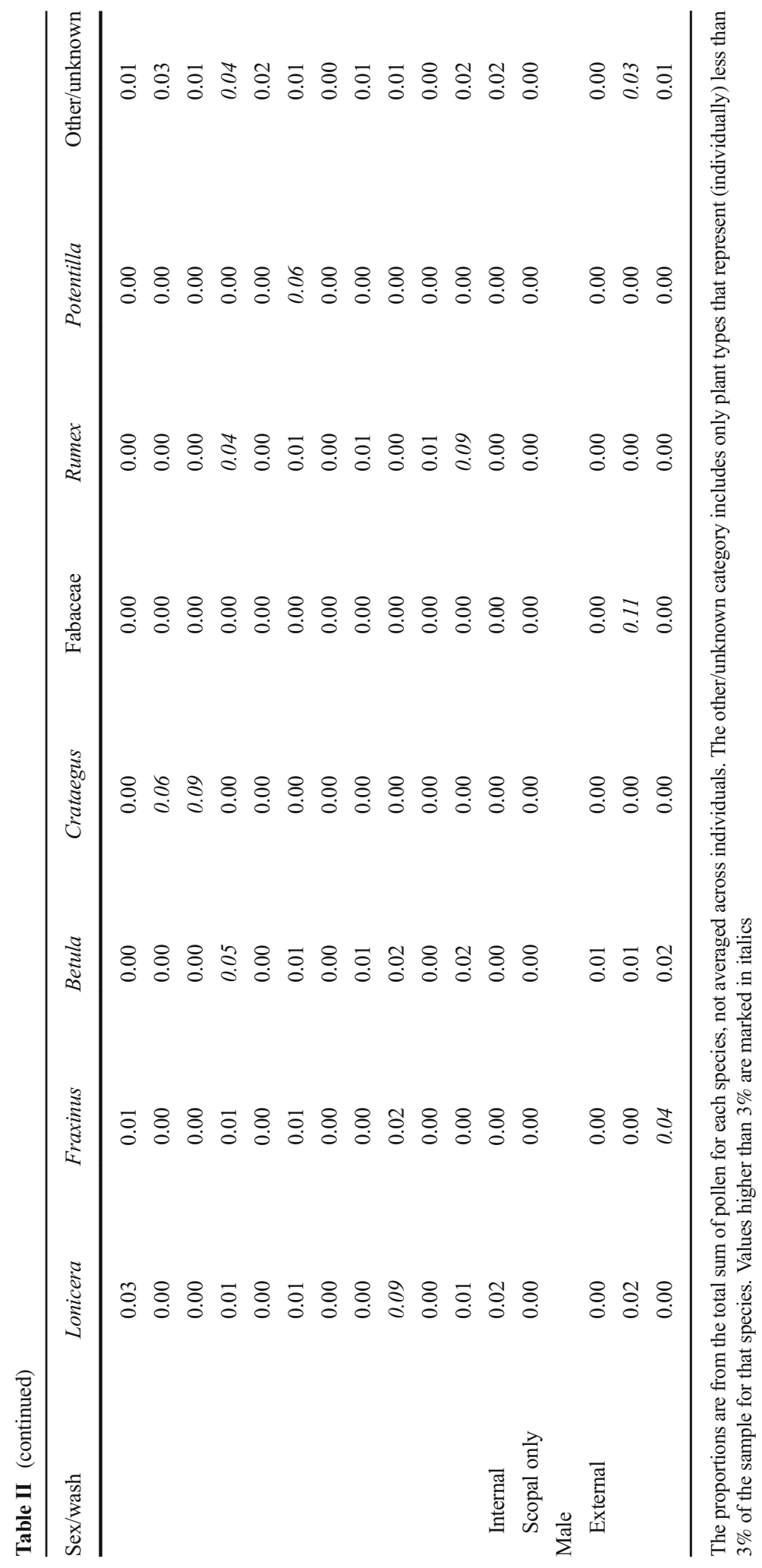



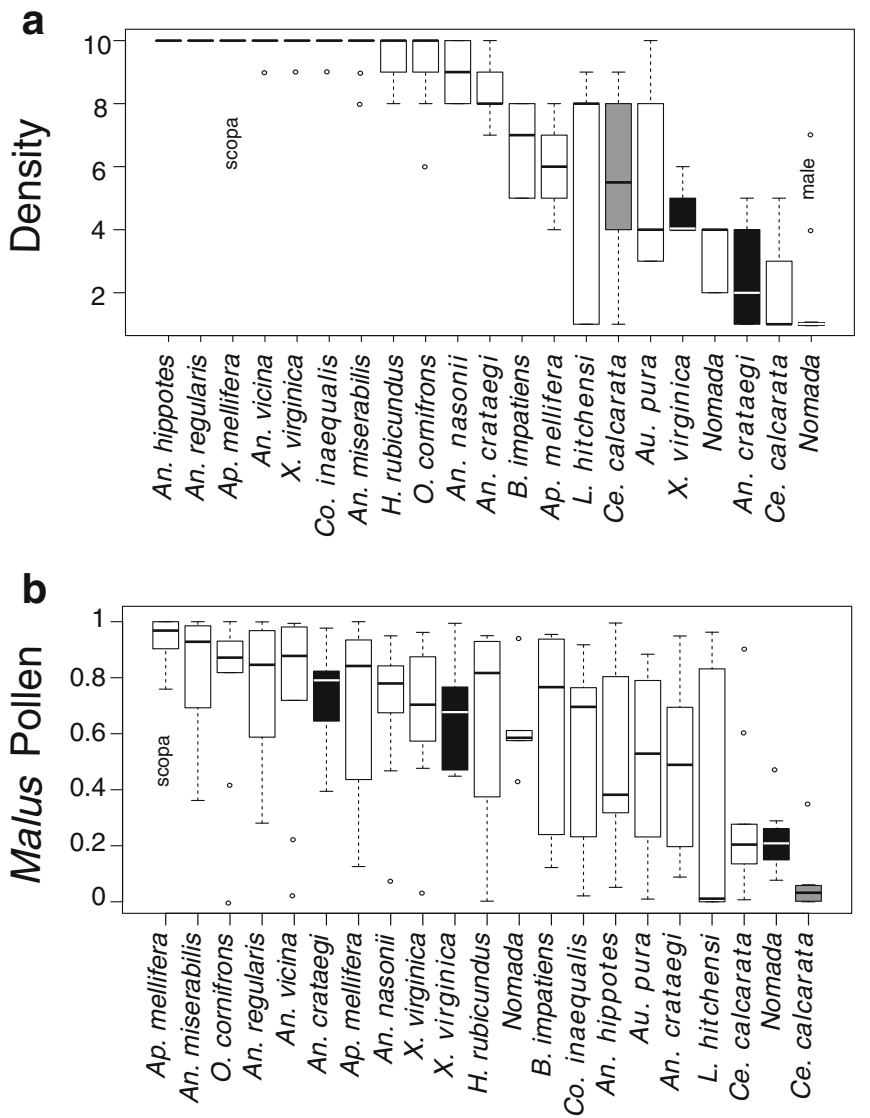

Figure 1. Boxplots of the pollen density (a) and proportion of Malus pollen (b) of the different bee types, averaged across all the individuals measured ( $n=10$ in all cases except in the female Nomada, where $n=5)$ and ranked from highest average on the left to lowest average on the right. The density is measured according to an index of relative density, with 10 being the highest (more than 300 grains in three random transects) and 1 being the lowest (representing fewer than 300 pollen grains on the entire individual, see "Material and methods" section for further description). Males are represented by black bars (or by the word "male" when the bar is not thick enough to show a color), while internal pollen is represented by dark gray. The scopal load of Apis mellifera is specified on the graphs. A subset of the Malus data is presented in Russo et al. (2017) Species-wash-sex combinations that differ significantly from each other are marked by different letters (Table S1).

Malus than all the females $(P=0.27$, estimate -0.07 ), but all of the wash types did significantly differ from each other. The internal washes had a significantly lower proportion of Malus pollen than the external washes in general $(P<0.01$, estimate -0.39 ), and the scopal load had a significantly higher proportion of Malus pollen than the external washes in general $(P<0.01$, estimate $0.34)$. Note that for this test, we compared the internal washes of $10 \mathrm{Ce}$. calcarata individuals and the scopal washes of 10 A. mellifera individuals to the rest of the external washes we conducted and 10 individuals of each of three species of males to the 175 individuals of the remaining 16 female species.

There was a significant difference in the composition of the internal and external washes of $C e$. calcarata $(P<0.05$, estimate 0.29$)$; however, there was a significant interaction between pollen type and wash, such that certain pollen types were more abundant in the internal washes, and some were more abundant in the external washes 


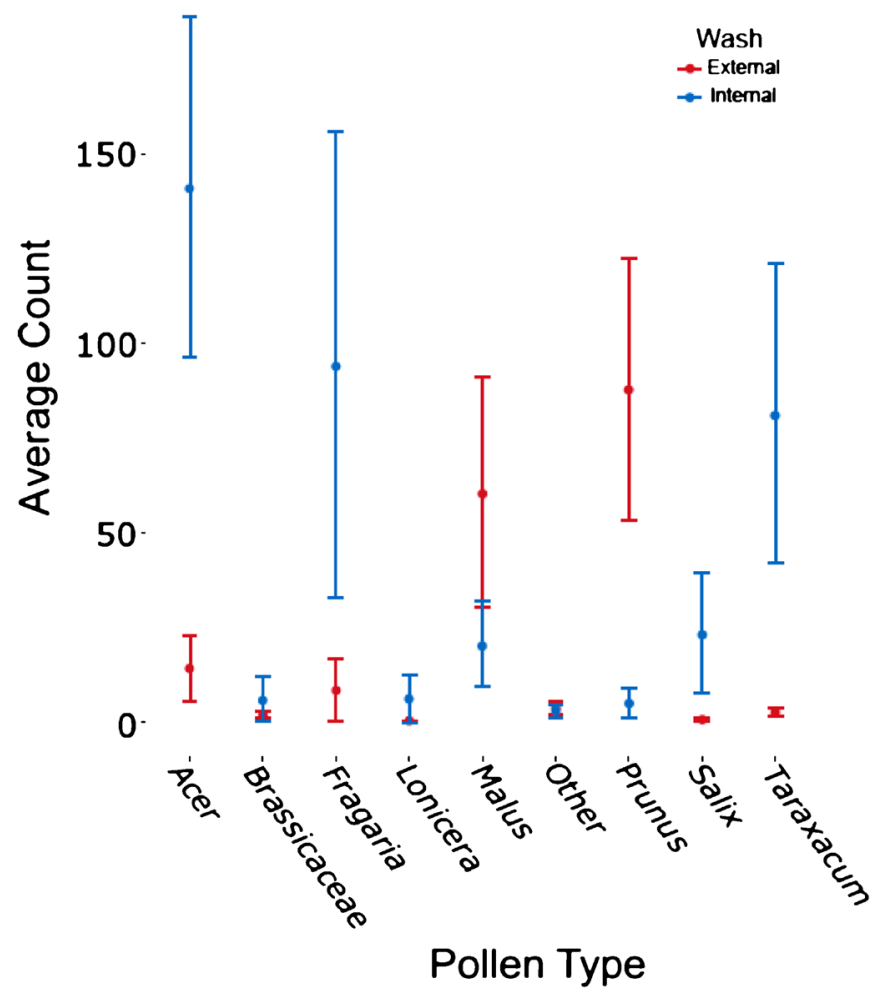

Figure 2. Average pollen counts of different plant pollen genera carried externally (red) and internally (blue) by Ceratina calcarata females. Ce. calcarata females carried a higher density of pollen overall internally (Figure 1a) and also had a very different composition of internal pollen relative to external pollen. The averages are represented by dots and their standard error by the positive and negative error bars .

(Figure 2). The external wash of Ce. calcarata individuals contained a significantly higher proportion of Prunus pollen than internal washes of the same individuals $(P<0.05$, estimate 0.35$)$. The remaining pollen types were not significantly different in external vs. internal washes.

Pollen from Malus dominated most of the 21 different types of species-wash-sex combinations counted (Table I, Figure 3) and comprised approximately $50 \%$ or more of the pollen counts (on average) in all species except $A n$. crataegi females, Au. pura, Ce. calcarata (internal and external), L. hitchensi, and Nomada spp. males (Table II, Figure 1). The corbiculate loads of A. mellifera consisted of nearly pure Malus pollen, while their body washes consisted of significantly more pollen types ( $P<0.05, t$ stat 2.19 , Figure $1 \mathrm{~b})$. The generalized linear mixed effect model we used pulled out three rough groups, with significant overlap between them. The first group showed a very strong preference for Malus pollen (An. miserabilis, An. vicina, An. regularis, O. cornifrons, male An. crataegi, An. nasonii, and A. mellifera), while others seemed only to carry incidental apple pollen grains (L. hitchensi, Ce. calcarata, X. virginica, Au. pura, and female An. crataegi ). The remaining species fell somewhere in between these two extremes (Figure 1, Table S1).

Despite the prevalence of Malus pollen, the pollen carried by these bees comprised a diverse set of species (Figure 3). Trees represented 7, shrubs 2 and forbs 6 , of the 15 different pollen types containing values above $3 \%$ carried by the bees in our study. Trees together comprised $81 \%$ of the pollen gathered, with apple pollen as a majority at 59\% and other trees adding an additional $22 \%$. Forbs comprised an additional $16 \%$ of the pollen collected and shrubs the remaining $2 \%$. 


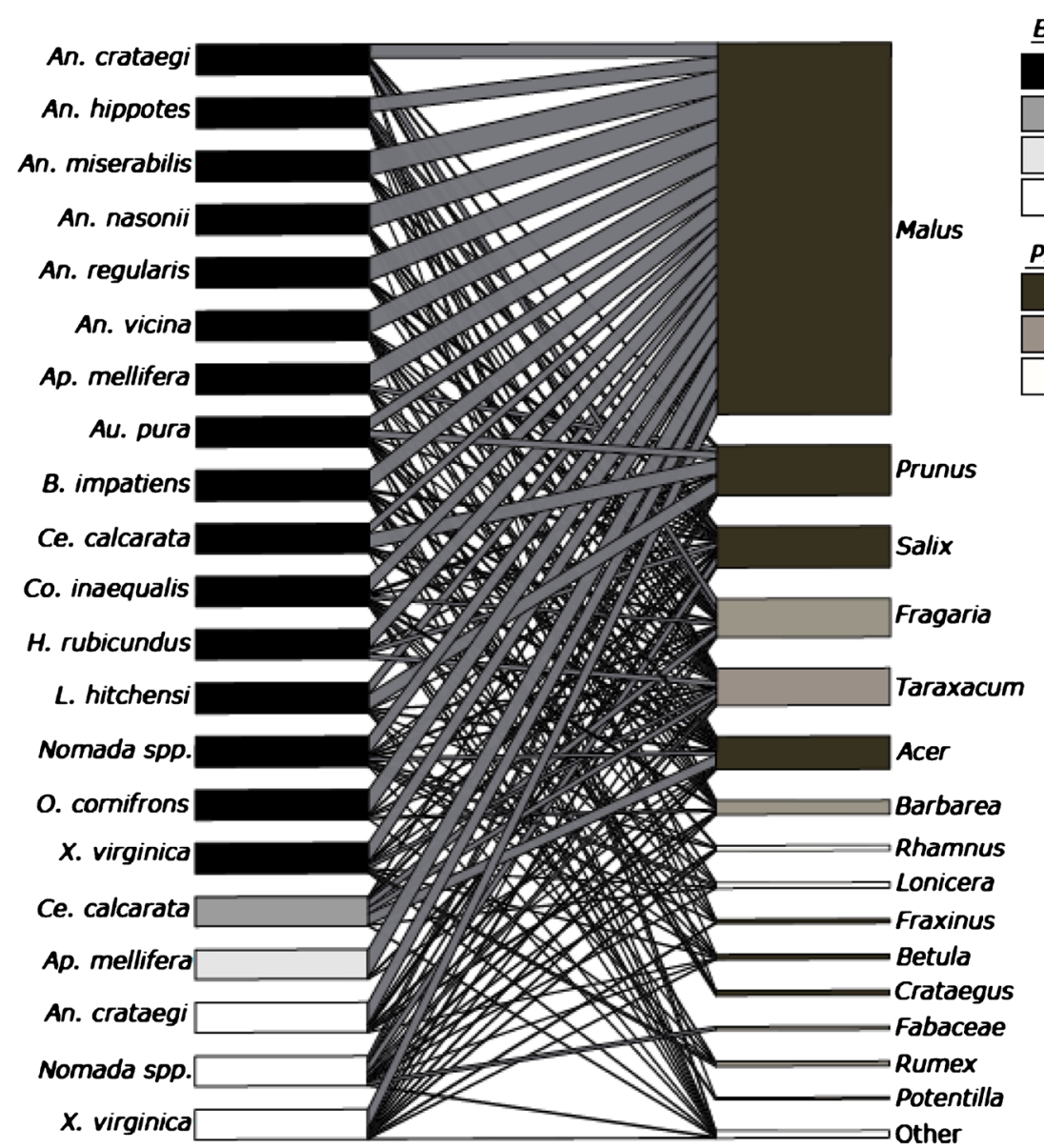

Bees

External wash, female Internal wash, female Scopal wash, female External wash, male

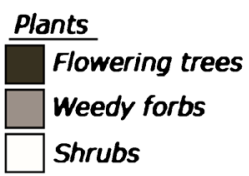

Figure 3. A food web diagram of the pollen hosts of bees collected in apple orchards. Bee species-wash-sex combinations are on the left, and plant genera are on the right. The width of the plant species boxes represents their relative contribution to the pollen composition of the pollen loads of all the bees. The lines between plant and bees species indicate the pollen carried by the bees, and the width of the lines represents the relative abundance of the plant genera in the pollen load carried by the bees.

The second most abundant pollen grain after Malus was that of Prunus spp. (cherries, peaches, and other stone fruit), which reach peak bloom around the same time as the apple trees (Russo, unpublished data) and are often grown in the same orchards. The genus Prunus is also represented by several wild species common to fragmented forest patches, including Prunus serotina and Prunus virginiana. This pollen type was important (i.e., comprised $>3 \%$ of the count on average) in seven of the specieswash-sex combinations and reached high average abundances in L. hitchensi $(52 \%)$ and $\mathrm{Ce}$. calcarata external washes (49\%) (Table II). On the other hand, Taraxacum (dandelion), Salix (willow), and Fragaria (strawberry) pollen were found in lower total abundances, but were important (i.e., comprised $>3 \%$ on average) for 12,11 , and 11 different species-wash-sex combinations each. In general, there was a high level of variation in host preferences among individuals of species that carried a low proportion of Malus pollen, and individual bee counts included a variety of other abundant pollen types. The internal pollen counts of Ce. calcarata were notably distinct from the external washes of that 
species and all other external washes and included high abundances of Acer (maple), Fragaria, and Taraxacum (Figure 2, Table II). The composition of male and female pollen in the species where we counted both does separate out in an ordination analysis, though this is driven mostly by the distinct preferences of $X$. virginica females and Nomada sp. males (Fig. S4A). On the other hand, the nesting habit of the bee species did not seem to have a significant effect on the composition of the pollen they carried (Fig. S4B), except perhaps for cleptoparasitic species, though these were only represented by Nomada sp. males and females.

\section{DISCUSSION}

Our pollen analysis has two main virtues: (1) it demonstrates which species within apple orchards exhibit high floral constancy or a preference for apple pollen and (2) it demonstrates which other flowering species might act as alternative pollen hosts for bees that visit apple blossoms, including several flowering tree and weedy forb species. Here, we analyzed 215 different pollen loads collected from 16 different species, all collected on apple blossoms. We include in our analysis male and cleptoparasitic bees and compare the internal and external pollen of the small carpenter bee, Ce. calcarata, and the pollen carried on the body versus the scopa on honeybees (A. mellifera). For the majority of the specieswash-sex combinations, we counted more than 300 pollen grains on 10 individuals.

Malus was, not surprisingly, the best represented pollen type as the bees were collected on apple flowers in apple orchards; however, the variation within and between species leads to some interesting questions. For example, to what extent might individuals we would not normally consider as pollinators, such as male and cleptoparasitic bees, carry Malus pollen? The pollen carried by male and cleptoparasitic bees is likely either determined by their preference for nectar or their own pollen consumption. Pollen feeding of adult solitary bees has been shown in Nomia melanderi and is likely to be important for other adult bees as well (Cane et al. 2016). Our results suggest that the males of pollen-collecting bee species in particular can carry relatively pure loads of conspecific pollen, though at lower densities than their female counterparts. This is in contrast to previous work that found males carrying much lower conspecific pollen purities than their female counterparts (Ne'eman et al. 2006); however, it agrees with work that demonstrates that visits from male bees have the potential to effect pollination on their host plants (Pascarella 2010; Fliszkiewicz et al. 2011). The female cleptoparasitic bees also demonstrated relatively high proportions of Malus pollen and remarkably low between-individual variation, while their male counterparts seem to lack any specialization, even within a given individual, and also carry a lower density of pollen. The unanticipated differences between male and female cleptoparasitic bees might be driven by the greater protein requirements of females, who must consume pollen as a protein source for egg production, even though they do not need to collect pollen provisions for a nest. Little is known about the pollen foraging of these cleptoparasitic bees, aside from some records of floral visitation (e.g., Bogusch 2003), as they are not considered in studies of pollen specialization (Wray and Elle 2016).

There was a significant negative association between the number of pollen grains counted on a given bee and the number of pollen types comprising more than $3 \%$ of a given pollen load. The absence of a positive association suggests that our sampling effort was sufficient, or even more than would be necessary, to evaluate the total number of important pollen types for these bees. The presence of a negative association may be due to the fact that high densities of pollen grains, where higher counts were possible, were more likely on bees carrying mostly pure Malus pollen. This could either be an indication that bees with low density of pollen were foraging mostly for nectar and carried only incidental pollen from various nectar hosts, or simply variation in the foraging behaviors and pollen preferences of individual bees.

However, there was also a large degree of variation between female pollen-collecting species. We might speculate that the species with the highest pollen densities were actively nest building and deliberately seeking out Malus as one source of pollen for their offspring, but the 
pollen purity of the species with high pollen density varied, and pollen density in many cases was not an indicator of pollen purity. For example, C. inaequalis exhibited extremely high pollen densities, but carried a wide variety of pollen types, consistent with previous work suggesting that this species is a generalist (Roulston and Cane 2000). This suggests that the potential for floral constancy within a given foraging bout varies between bee species.

High Malus pollen purity could be because pollinators which specialize or simply thrive on Malus pollen reach high population densities in apple orchards and carry relatively pure pollen loads as they exploit the resource pulse. The purity of the pollen loads carried by bees has been shown to be important for pollination of individual flowers (Park et al. 2016), though not at the scale of an entire orchard, where abundance and foraging behavior drive pollinator importance (Russo et al. 2017). However, the bees with the highest pollen purity in our study (An. miserabilis, An. vicina, An. regularis, O. cornifrons, male An. crataegi, An. nasonii, and $A$. mellifera) were also some of the most abundant. Some of the highest densities and purities of pollen loads were found among the Andrena, a genus which contains many oligolectic species (Larkin et al. 2008), including important pollinators of Rosaceae (LaBerge 1986; Russo et al. 2015; Wiesenborn 2015). The Andrena have been shown to be the most abundant and effective wild apple pollinators in western New York (Russo et al. 2017; Park et al. 2015; Martins et al. 2015). On the other hand, several of the species with high Malus pollen purity are known generalists (e.g., A. mellifera Schmidt 1984; O. cornifrons Haider et al. 2013); however, they are capable of strong preferences for one host species on a given foraging trip (Oldroyd et al. 1992; Bosch and Kemp 2002). Though A. mellifera and $O$. cornifrons are polylectic and generalist at the species level, they were found to be highly specialized on an individual level in our study, possibly because of the high-density resource a mass-flowering crop such as apple represents (Holzschuh et al. 2013; Westphal et al. 2003) or simply because individuals of these species are more likely to exhibit high floral constancy within a foraging bout.

Aside from high apple densities, a variety of pollen hosts were represented in our counts. Early flowering tree species seemed to be particularly important, which may partially explain why natural habitat is a significant correlate with wild bee abundance and species richness in apple orchards (Park et al. 2015). For example, we found that six genera of flowering trees, aside from Malus, contributed significantly to the pollen loads of our surveyed bees. This includes genera common in the fragmented forest habitat of western New York, including Prunus, Acer, Salix, Fraxinus, Crataegus, and Betula. The majority of the remaining pollen was from weedy forbs that are also common in apple orchards (Russo, unpubl. data), including Taraxacum, Barbarea, Potentilla, and Rumex, as well as the genus Fragaria, which is represented by both weedy and domesticated species. Even the abundant and effective apple pollinators in the genus Andrena (which carry relatively pure Malus pollen loads) may rely on four species of trees other than Malus and three weedy forbs for a significant portion of their pollen diet.

Thus, maintaining a high level of plant diversity in the orchard may be important for apple orchard managers interested in relying more on wild bee pollination services. Early flowering tree species common in forest fragments in New York, for example, may provide an important contribution to the nutrition of some of the primary wild apple pollinators, the Andrena. Furthermore, forb species commonly considered to be weeds in apple orchards may have the side benefit of helping to diversify bee diets. Indeed, pollen host diversity has been shown to be important to the fitness of even relatively generalist bees (Carvell et al. 2017).

The fact that sampling was constrained to apple orchards is both a limitation and strength of this study. It is a limitation because we cannot state the full breadth of pollen preferences in these bees. It is a strength because all bees were sampled in the same environment under the same conditions, which makes their pollen loads more comparable. In addition, the large spatial and temporal scale of the study (across 6 years and across a broad area of central New York) allowed us to randomly select representative individuals from a large 
species pool in most cases (except the female Nomada spp.). Future work could explore the pollen composition of these same species collected on other floral hosts in different habitats to determine whether they exhibit similar levels of individual specialization and/or similar host preferences.

In general, we find that proportions of the focal pollen species (Malus) are high among sampled bees, but our study also suggests that bees in orchards utilize many alternate host species despite the fact that the resource availability of Malus is much higher than any other flowering plant during peak apple bloom. It is possible that bees seek to diversify the pollen they collect because of some nutritional deficiency in Malus pollen (Eckhardt et al. 2014). This is supported by the relatively lower density of Malus pollen in the internal relative to external washes on the small carpenter bee ( $\mathrm{Ce}$. calcarata). On the other hand, the higher density of Malus pollen in the scopa of honeybees relative to their body washes suggests that they are specifically selecting it as a protein source for the hive. Future work could investigate the relative pollen quality of Malus pollen versus alternative host plants in the orchards (e.g., Vaudo et al. 2015).

\section{ACKNOWLEDGEMENTS}

We would like to thank Z.X. Ren, P. Bernhardt, and J. Gill for training in how to stain and identify pollen grains. This project was supported by Smith Lever and Hatch Funds administered by Cornell University Agricultural Experiment Station, a USDA-AFRI grant [USDA 2010-03689, B.N.D., PI], and additional support from the Atkinson Center for a Sustainable Future (Cornell University).

\section{AUTHOR'S CONTRIBUTIONS}

LR and BD conceived the research. BD and LR collected bee specimens. LR conducted the pollen counts and developed the pollen library. LR wrote the first draft of the ms, BD revised the ms.

Préférences polliniques des espèces d'abeilles visitant les fleurs de pommier (Malus pumila) dans l'Etat de NewYork
Pollinisation / hôte alternatif pour le pollen / ressource florale / analyse pollinique / service de pollinisation / communauté d'abeilles sauvages

Pollenpräferenz zwischen blütenbesuchenden Bienen am Apfel (Malus pumila) im östlichen New York

Agro-Bestäubung / alternative Pollenwirte / B lütenmaßnahmen / Pollenanalyse / Bestäubungsleistung / Wildbienen Lebensgemeinschaft

\section{REFERENCES}

Aizen, M. A., Garibaldi, L. A., Cunningham, S. A., Klein, A. M. (2008). Long-term global trends in crop yield and production reveal no current pollination shortage but increasing pollinator dependency. Curr. Biol., 18 (20), 1572-1575.

Bates, D., Maechler, M., Bolker, B., Walker, S. (2015). Fitting linear mixed-effects models using lme4. J. Stat. Software, 67 (1), 1-48.

Bernhardt, P. (1987). A comparison of the diversity, density, and foraging behavior of bees and wasps on Australian Acacia. Ann. Missouri Bot. Gard., 74 (1), 4250.

Blitzer, E. J., Gibbs, J., Park, M. G., Danforth, B. N. (2016). Pollination services for apple are dependent on diverse wild bee communities. Agric. Ecosyst. Environ., 221, $1-7$.

Bogusch, P. (2003) Hosts, foraging behavior and distribution of six species of cleptoparasitic bees of the subfamily Anthophorinae (Hymenoptera: Apidae). Acta Soc. Zool. Bohem, 67, 65-70.

Bosch, J., Kemp, W. P. (2002) Developing and establishing bee species as crop pollinators: the example of Osmia spp. (Hymenoptera: Megachilidae) and fruit trees. Bull. Entomol. Res., 92, 3-16.

Cane, J. H., Dobson, H. E. M., Boyer, B. (2016). Timing and size of daily pollen meals eaten by adult females of a solitary bee (Nomia melanderi) (Apiformes: Halictidae). Apidologie, $48: 17-30$ 1-14.

Carvell, C., Bourke, A. F. G., Dreier, S., Freeman, S. N., Hulmes, S., Jordan, W. C., Redhead, J. W., Sumner, S., Wang, J., Heard, M. S. (2017). Bumblebee family lineage survival is enhanced in high-quality landscapes. Nature, doi:10.1038/nature21709.

Connelly, H., Poveda, K., Loeb, G. (2015). Landscape simplification decreases wild bee pollination services to strawberry. Agric. Ecosyst. Environ, 211, 51-56.

Crompton, C. W., Wojtas, W. A. (1993) Pollen grains of Canadian honey plants. Canada Communication Group

Eckhardt, M., Haider, M., Dorn, S. (2014). Pollen mixing in pollen generalist solitary bees: a possible strategy to complement or mitigate unfavourable pollen properties? J. Anim. Ecol., 83 (3), 588-597. 
Edens-Meier, R., Joseph, M., Arduser, M., Westhus, E., Bernhardt, P. (2011). The pollination biology of an annual endemic herb, Physaria filiformis (Brassicaceae), in the Missouri Ozarks following controlled burns. J. Torrey Bot. Soc., 138 (3), 287-297.

Fliszkiewicz, M., Giejdasz, K., Wilkaniec, Z. A. (2011). The importance of male red mason bee (Osmia rufa L.) and male bufftailed bumblebee (Bombus terrestris L.) pollination in blackcurrant (Ribes nigrum L.). J. Hortic. Sci. Biotechnol., 86 (5), 457-460.

Garibaldi, L. A., Steffan-Dewenter, I., Winfree, R., Aizen, M. A., Bommarco, R., et al. (2013). Wild pollinators enhance fruit set of crops regardless of honey bee abundance. Science, 339 (6127), 1608-1611.

Genissel, A., Aupinel, P., Bressac, C., Tasei, J. N., Chevrier, C. (2002). Influence of pollen origin on performance of Bombus terrestris micro-colonies. Entomol. Exp. Appl., 104 (2-3), 329-336.

Haider, M., Dorn, S., Sedivy, C., and Müller, A. (2013). Phylogeny and floral hosts of a predominantly generalist group of mason bees (Megachilidae: Osmiini). Biol. J. Linn. Soc., 111 (1), 78-91.

Holzschuh, A., Dormann, C., Tscharntke, T. (2013). Massflowering crops enhance wild bee abundance. Oecologia, 172 (2), 477-484.

Jander, R. (1976). Grooming and pollen manipulation in bees (Apoidea): the nature and evolution of movements involving the foreleg. Physiol. Entomol., 1 (3), 179-194.

Kapp, R. O., Davis, O. K., King, J. E. (2000) Pollen and spores (2nd Edition). The American Association of Stratigraphic Palynologists

Klein, A. M., Vaissiere, B. E., Cane, J. H., SteffanDewenter, I., Cunningham, S. A., ... Tscharntke, T. (2007) Importance of pollinators in changing landscapes for world crops. Proc. R. Soc. B-Biol. Sci, 274 (1608), 303-313

Kremen, C., Williams, N. M., Thorp, R. W. (2002). Crop pollination from native bees at risk from agricultural intensification. Proc. Nat. Acad. Sci., 99 (26), 1681216816.

LaBerge, W. (1986) The zoogeography of Andrena Fabricius (Hymenoptera: Andrenidae) of the Western Hemisphere. Prairie Past, Present Futur

Larkin, L. L., Neff, J. L., Simpson, B. B. (2008). The evolution of a pollen diet: host choice and diet breadth of Andrena bees (Hymenoptera: Andrenidae). Apidologie, 39 (1), 133-145.

Lewis, W. H., Vinay, P., Zenger, V. E. (1983). Airborne and Allergenic Pollen of North America. Johns Hopkins University Press Baltimore.

Mackenzie, K. E., Averill, A. L. (1995). Bee (Hymenoptera: Apoidea) diversity and abundance on cranberry in southeastern Massachusetts. Ann. Ent. Soc. Am., 88(3), 334-341.

Mallinger, R. E., Gratton, C., Diekötter T. (2015). Species richness of wild bees, but not the use of managed honeybees, increases fruit set of a pollinatordependent crop. J. Appl. Ecol., 52 (2):323-330.
Martins, K. T., Gonzalez, A., Lechowicz, M. J. (2015). Pollination services are mediated by bee functional diversity and landscape context. Agric. Ecosyst. Environ., $200,12-20$.

Morandin, L. A., Winston, M. L. (2005). Wild bee abundance and seed production in conventional, organic, and genetically modified canola. Ecol. Appl., 15(3), 871-881.

Ne'eman, G., Shavit, O., Shaltiel, L., Shmida, A. (2006) Foraging by male and female solitary bees with implications for pollination. J. Insect Behav., 19 (3), 383-401.

Oksanen, J., Kindt, R., Legendre, P., O'Hara, B., Stevens, M. H. H., Oksanen, M. J. (2007). The vegan package. Community ecol. package, 10, 631-637.

Oldroyd, B. P., Rinderer, T. E., Buco, S. M. (1992). Intracolonial foraging specialism by honey bees (Apis mellifera) (Hymenoptera: Apidae). Behav. Ecol. Sociobiol., 30 (5), 291-295.

Park, M. G., Blitzer, E. J., Gibbs, J., Losey, J. E., Danforth, B. N. (2015). Negative effects of pesticides on wild bee communities can be buffered by landscape context. Proc. R. Soc. London B Biol. Sci., 282 (1809), 20150299.

Park, M. G., Raguso, R. A., Losey, J. E., Danforth, B. N. (2016) Per-visit pollinator performance and regional importance of wild Bombus and Andrena (Melandrena) compared to the managed honey bee in New York apple orchards. Apidologie, 1-16

Pascarella, J. B. (2010). Pollination biology of Gelsemium sempervirens L.(Ait.)(Gelsemiaceae): do male and female Habropoda laboriosa F.(Hymenoptera, Apidae) differ in pollination efficiency? J. Apic. Res., 49 (2), 170-176.

Pernal, S., Currie, R. (2001). The influence of pollen quality on foraging behavior in honeybees (Apis mellifera L.). Behav. Ecol. Sociobiol., 51 (1), 53-68.

R Core Team. (2013). R: A language and environment for statistical computing. R Foundation for Statistical Computing, Vienna.

Roulston, T. H., Cane, J. H. (2000). The effect of diet breadth and nesting ecology on body size variation in bees (Apiformes). J. Kansas Entomol. Soc., 73 (3), 129-142.

Roulston, T. H., Cane, J. H. (2002). The effect of pollen protein concentration on body size in the sweat bee Lasioglossum zephyrum (Hymenoptera: Apiformes). Evol. Ecol., 16 (1), 49-65.

Russo, L., Debarros, N., Yang, S., Shea, K., Mortensen, D. (2013). Supporting crop pollinators with floral resources: Network-based phenological matching. Ecol. Evol., 3 (9), 3125-3140.

Russo, L., Park, M., Gibbs, J., Danforth, B. (2015). The challenge of accurately documenting bee species richness in agroecosystems: Bee diversity in eastern apple orchards. Ecol. Evol., 5 (17), 3531-3540.

Russo, L., Park, M. G., Blitzer, E. J., Danforth, B. N. (2017). Flower handling behavior and abundance determine the relative contribution of pollinators to seed set in apple orchards. Agric. Ecosyst. Environ., 246, 102-108. 
Schmidt, J. O. (1984). Feeding preferences of Apis mellifera L. (Hymenoptera: Apidae): Individual versus mixed pollen species. J. Kansas Entomol. Soc., 57 (2), 323-327.

Schmidt, J. O., Thoenes, S. C., Levin, M. D. (1987). Survival of honey bees, Apis mellifera (Hymenoptera: Apidae), fed various pollen sources. Ann. Entomol. Soc. Am., 80 (2), 176-183.

Tuell, J.K., Ascher, J.S., Isaacs, R. (2009). Wild bees (Hymenoptera: Apoidea: Anthophila) of the Michigan highbush blueberry agroecosystem. Ann. Ent. Soc. Am., 102 (2), 275-287.

Tuell, J. K., Fiedler, A. K., Landis, D., Isaacs, R. (2008). Visitation by wild and managed bees (Hymenoptera: Apoidea) to eastern U.S. native plants for use in conservation programs. Environ. Entomol., 37 (3), $707-$ 718.

Vaudo, A. D., Patch, H. M., Mortensen, D. A., Tooker, J. F., Grozinger, C. M. (2016) Macronutrient ratios in pollen shape bumble bee (Bombus impatiens) foraging strategies and floral preferences. Proc. Nat. Acad. Sci., 113 (28), E4035-E4042.

Vaudo, A. D., Tooker, J. F., Grozinger, C. M., Patch, H. M. (2015). Bee nutrition and floral resource restoration. Curr. Opin. Insect Sci., 10, 133-141.

Waser, N. M., Chittka, L., Price, M. V., Williams, N. M., Ollerton, J. (1996). Generalization in pollination systems, and why it matters. Ecology, 77 (4), 1043-1060.

Westphal, C., Steffan-Dewenter, I., Tscharntke, T. (2003). Mass flowering crops enhance pollinator densities at a landscape scale. Ecol. Lett., 6 (11), 961-965.

Wiesenborn, W. (2015). Conspecific pollen loads on insects from Prunus fasciculata (Rosaceae) female flowers in southern Nevada. West North Am. Nat., 75 (2), 192199.

Wray, J. C., Elle, E. (2016). Pollen preferences of two species of Andrena in British Columbia's oaksavannah ecosystem. J. Entomol. Soc. Brit. Columbia, $113,39-48$. 